\title{
CONTRIBUCIONES INDIVIDUALES A LOS CÓDIGOS DE LA FICCIÓN MODERNA. AVATARES DEL “MANUSCRITO ENCONTRADO" A PARTIR DE LA FALSIFICACIÓN
}

\section{INDIVIDUAL CONTRIBUTIONS TO THE FICTION CODES. INCARNATIONS OF THE "FOUND MANUSCRIPT" BEGINING FROM FORGERY}

\author{
Miguel MARTíN ECHARRI \\ Doctor en Filología Hispánica (Universidad de Salamanca) \\ mrtnchrr@gmail.com
}

\begin{abstract}
Resumen: Pese a la necesaria flexibilidad del código semiótico, que trasciende a los mensajes que se inscriben en él, debe presentar también cierta plasticidad: algunas intervenciones exigen de él una readaptación. Pero la complejidad de los cambios puede dificultar su estudio, salvo cuando esas intervenciones sean claramente discretas y permanezcan para el historiador, como ocurre con algunos códigos literarios, cuyas transformaciones pueden explicarse a partir de entidades individuales (los libros). El código novelesco se compone de rasgos que pasan por diversas fases (innovación, generalización, cansancio, olvido, reinvención) cuyo desarrollo es variable para cada tradición.

Palabras clave: Cambio semiótico. Novela. Manuscrito encontrado. Fraude. Código.

Abstract: Despite the necessary flexibility of the semiotic codes, which survive the messages inscribed in them, they must also be plastic to a certain degree to readjust to some interventions.However, the enormous complexity of changes can make them terribly difficult to analyse, except when those interventions are clearly discrete and permanent for the historian, as happens with some literary codes, whose transformations can be studied as trends made of individual entities (books). The code of the novel is composed of features that go through various phases (innovation, generalization, boredom, oblivion, reinvention) whose development differs from one tradition to another.
\end{abstract}

Key Words: Semiotic change. Novel. Found manuscript. Forgery. Code. 


\section{INTERVENCIONES INDIVIDUALES SOBRE LOS CÓDIGOS}

Por singular que sea el desarrollo de una partida de ajedrez, las novedades que pueda presentar no provocan cambios en un conjunto de normas universalmente aceptadas. El ingenio de los participantes se somete a un código previamente establecido y se compromete a circunscribir toda astucia empleada a esos límites conocidos. Siguiendo esa analogía, podría pensarse que todo código es impasible a los mensajes individuales que acoge, si no fuera por la evidencia de que ninguno es eterno: el paso del tiempo y de las generaciones provoca en ellos transformaciones más o menos evidentes. Las convenciones del pasado requieren una reconstrucción arqueológica para ser interpretadas hoy, y sabemos que los idiomas del presente están igualmente condenados a modificarse hasta volverse irreconocibles.

Ya Saussure (1995: 113-115) reconocía la doble naturaleza de la lengua, como sistema coherente desde un punto de vista sincrónico pero sometido a transformaciones diacrónicas. Utilizaba la metáfora de una partida de ajedrez (en un sentido muy diferente del que hemos usado), que puede ser descrita en cada una de las posiciones en términos sincrónicos (como un sistema en determinado equilibrio), pero que va transformándose movimiento a movimiento. Del mismo modo, la lengua se transforma hasta el punto de que un determinado estadio del sistema puede no compartir ningún elemento con otro, por razones complejas y difíciles de delimitar.

Según el lingüista suizo, no es posible atribuir la planificación de los cambios a ninguna voluntad similar a las de los jugadores de ajedrez que modifican la posición de las fichas en el tablero. Más bien, en su opinión, el cambio se produce a partir de ciertas variaciones particulares en el habla (no generalizadas) que poco a poco van teniendo fortuna hasta participar en el modelo común de la lengua (Saussure, 1995: 125). "Antes de que honor se hiciera un competidor susceptible de reemplazar a honōs, hizo falta que un primer sujeto lo improvisara, que otros lo imitaran y lo repitieran, hasta imponerlo en el uso" (Saussure, 1995: 207). Es decir que las transformaciones se deben a la progresiva generalización de variaciones que inicialmente no son sino extravagancias.

La mayoría de las explicaciones que se buscan para entender el cambio (como el contacto entre lenguas o dialectos, la indolencia o descuido articulatorio, las dificultades de los niños o los jóvenes para reproducir exactamente los modelos de las generaciones anteriores, etc.) prescinden de la voluntad de los hablantes como individuos. Labov (2006: 72) rechaza que el análisis lingüístico pueda "reconocer gramáticas o fonologías individuales" porque "el individuo no existe como sujeto lingüístico". Si habla de "líderes del cambio" no es porque inventen formas nuevas, sino porque impulsan o hacen avanzar cambios que ya se encuentran "en curso". No es tanto ese primer individuo de Saussure 
como alteraciones que al principio son lingüísticamente despreciables y gradualmente van asumiendo una importancia estadística.

Obviamente, si la naturaleza de la lengua incluye la dualidad saussureana de equilibrio en el cambio, lo mismo puede decirse de otros códigos semióticos. Tal vez las extravagancias practicadas por algunos usuarios individuales de cierto código hayan sido inicialmente extrasistémicas pero se hayan extendido a pequeños grupos para finalmente imponerse a comunidades enteras, provocando la acomodación de todo el sistema semiótico (y de otros sistemas vecinos), fenómeno acaso marginal en algunos casos pero que en otros llega a ser central y da lugar a un código nuevo.

Por volver al ajedrez (en una tercera manera de aprovechar el ejemplo), el aburrimiento de los jugadores ante determinadas situaciones repetidas de partida en partida sí ha provocado ciertos cambios en las reglas, como el que recogía Francesch Vicent en 1495 y por el que la dama pasaba a asumir las posibilidades sumadas del alfil y la torre: la propuesta tuvo tanto éxito que resultó hegemónica y relegó al olvido la mayoría de las estrategias que eran válidas para las reglas anteriores. Si el valenciano no era el autor de la innovación sino que solo recogía una modalidad común en su ámbito, el ejemplo sigue a la perfección el modelo lingüístico.

Lo mismo ha ocurrido con el "gol de oro" en las eliminatorias de fútbol: el aburrimiento del público ante los efectos de determinada regla lleva a las autoridades (en sus funciones de líderes sociales de ese código) a practicar pequeños retoques en el conjunto.

Pero muchos ejemplos del mundo de los juegos pueden poner en entredicho la supuesta imposibilidad de que el individuo participe directamente en la transformación del código. La muerte de Tom Simpson en el Tour de Francia de 1967 provocó una inmediata revolución de las leyes contra el dopaje en esa y otras competiciones: una actuación individual (aunque obviamente no perseguía ese fin) provocó un cambio en las normas. De una forma consciente, en cambio, Harold Sterling Vanderbilt propuso modificaciones concretas en las normas del bridge que fueron asumidas por la colectividad.

Es obvio que las lenguas naturales tienen unas características a la vez infinitamente más complejas y universales que los juegos. No obstante, sí es posible ese tipo de intervención en relación con grupos humanos más limitados, o incluso en determinados casos dentro de grandes colectividades (así cuando se generaliza una creación lingüística particular, como el nombre de un nuevo producto). Se puede proponer que el código está formado por signos memorísticos (las convenciones que lo componen), y que por eso es posible generar nuevos signos memorables que pasen a integrarse en el código, sea porque son dignos de imitación o de repulsa o bien porque el autor del signo domina los medios capaces de generalizarlo. 
En este sentido, y aunque no se refiere exclusivamente a códigos lingüísticos sino al conjunto de la semiosis, Eco concede a la voluntad individual una mayor capacidad de intervención sobre el código, que se caracteriza así por una inestabilidad potencial que lo vuelve susceptible de cambiar a partir de la relación dialéctica entre el sistema y cada mensaje actual. De hecho, los mensajes pueden provocar o exigir una reestructuración del código en cuyo seno se han realizado y cuyas potencialidades aprovechan. De nuevo, esa reestructuración permite la generación de nuevos significados, lo que a su vez da a los usuarios la posibilidad de generar nuevos mensajes.

Para ejemplificar este fenómeno, habla del cambio semántico en el modelo dulcesano en el discurso publicitario del ciclamato (Eco, 1989: 90-92): el descubrimiento de que ese edulcorante provocaba cáncer llevó a la sustitución de la oposición "posible infarto / salud" por "posible infarto / cáncer seguro", con lo que los productores empezaron a anunciar como rasgo positivo de su producto "with sugar added".

La explicación de esto hay que encontrarla en el hecho de que la semiosis no se limita a los objetos físicos, sino que "en todas las culturas una unidad cultural es simplemente algo que esa cultura ha definido como unidad distinta de otras $y$, por lo tanto, puede ser una persona, una localidad geográfica, una cosa, un sentimiento, una esperanza, una idea, una alucinación" (Eco, 2000: 112). Siguiendo a Peirce, el signo remite a otro signo, su interpretante, pero "el interpretante de un signo no tiene por qué ser un signo del mismo tipo (perteneciente al mismo sistema semiótico)" (Eco, 2000: 187). Es decir, el reconocimiento de un signo remite a otro signo que puede, en última instancia, no ser otra cosa que mental. Puesto que "también las ideas son signos" (Eco, 2000: 250), está garantizado que todo interpretante puede remitir todavía a otro interpretante.

Entonces el código mismo es de naturaleza sígnica: está compuesto de signos memorizados y compartidos que otorgan a las nuevas manifestaciones semióticas un sistema de referencias capaz de proporcionarles interpretaciones. Pero esa nueva manifestación pasa también en ese mismo momento a la memoria de los receptores, que en una medida variable la conservarán y podrán utilizarla como una referencia más en el sistema. El nuevo signo cuya aparición acaba de ser registrada puede terminar por integrarse en el código, y también puede provocar una transformación en otro sentido, una acomodación de los otros elementos del código a la posibilidad de novedades como esa, o incluso una serie de reacciones en cadena: pensemos en las acomodaciones provocadas por determinados tabúes.

[...] existe una interacción bastante estrecha, y en varias direcciones, entre la visión del mundo, el modo como una cultura vuelve pertinentes sus unidades semánticas y el sistema de los significados que las nombran y las 'interpretan.' Los procesos de cambio de código se producen en el momento 
en que no se acepta esa interacción como natural y se la somete a una revisión crítica (Eco, 2000: 130).

Podríamos asumir que no se trata de una situación extraordinaria, sino que en todo momento se manifiesta la inestabilidad que permite revisiones críticas, de modo que, partiendo de un código, la aparición de una nueva entidad semiótica puede provocar (o incluso siempre provoca) una acomodación de magnitud variable del resto de los elementos participantes en la semiosis: las circunstancias, los actores que reaccionan, el propio código, etc.

\section{EL EJEMPLO DE LA FICCIÓN MODERNA}

La complejidad de este proceso es tan inabarcable como su flexibilidad, que es además variable de un código a otro. Entre ellos, la lengua está sujeta a imperceptibles variaciones con cada intervención hablada, variaciones que pueden abrir la puerta a cambios potenciales que sin embargo nunca lleguen a actualizarse. Pero la historia de la literatura nos ofrece un modelo relativamente sencillo para entender las transformaciones en los códigos: el de las obras literarias individuales y los códigos en los que se insertan y que a su vez modifican. Si bien es obvio que su estudio no tiene por qué ser aplicable a otros códigos, conviene prestarle atención por su mera posibilidad y por los rasgos que podría compartir con ellos.

Entre los diversos códigos que se han desarrollado en la historia de la literatura, quizás el que mejor se acomoda a nuestros intereses sea el de la ficción novelesca en sus transformaciones desde los inicios de la modernidad hasta el triunfo del Realismo. Los textos teatrales son frágiles o efímeros, al menos en los aspectos que nos permitirían relacionarlos con los códigos a los que deben responder, como lo es la oralidad, y la literatura manuscrita no permite seguir la pista a los casos concretos con un nivel de certeza suficiente; por el contrario, en los tiempos de la hegemonía de la imprenta (al menos hasta la democratización electrónica de lo escrito), las intervenciones individuales sobre el código se vuelven una variable relativamente discreta: cada libro publicado es una intervención inserta en el código, pero ese código está estructurado a partir de un número muy limitado de intervenciones (puesto que casi podemos olvidar las sugerencias manuscritas y las habladas). Además, contamos con la certeza de que la mayoría de los textos publicados impresos se nos han conservado, de modo que tenemos acceso a casi todas las intervenciones que se hicieron sobre ese código, y podemos estudiar los efectos que tuvieron sobre otras intervenciones que las sucedieron.

Partimos de esa idea ventajosa para tratar de explicar el modelo del cambio en el código a partir de las intervenciones individuales sobre el relato, que a lo largo de la 
Edad Moderna se mueve entre la historia, el testimonio, el fraude, la parodia y la ficción, desplazamientos debidos a las aportaciones de autores individuales en sucesivas transformaciones del código.

\section{VEROSIMILITUD, CREDIBILIDAD, VERDAD}

En la era de la imprenta, parece haber entrado en crisis el delicado equilibrio que mantenían los parámetros de la credibilidad. El perfeccionamiento de los métodos de estudio y la creciente sofisticación de unos criterios cada vez más fidedignos para acercarse a la historia y a los textos antiguos puso en evidencia las tradiciones anteriores de estudio de la naturaleza y de las autoridades, pero también tuvo que generar una nueva desconfianza: la falsificación no resultaba más difícil con los nuevos métodos críticos que con los tradicionales, pero además ahora podían reproducirse con una velocidad insólita y llegar hasta los países más lejanos.

Sin embargo, el inestable equilibrio que posibilitó el nacimiento de la ficción literaria europea no es una excepción histórica: debemos considerar que las relaciones entre la verosimilitud, la credibilidad y la verdad dependen del sistema de convenciones correspondiente a cada momento comunicativo. La verosimilitud (la apariencia de verdad que sin embargo no se compromete con ella) no se establece por la relación entre el texto y la realidad, sino entre el texto y un discurso previo sobre la realidad, es decir un código previo: Todorov (Ducrot y Todorov, 1995: 303) señala que la verosimilitud no depende de la relación de verdad entre el discurso y su referente, sino "de la relación entre la literatura y el comportamiento verbal general de una sociedad".

Se trata entonces de una relación plenamente convencional, dependiente del código en el estadio presente, tal como lo conocen los participantes en la comunicación. Podemos dar por verosímil una película de acción simplemente porque mantiene la coherencia de otras películas de acción, o una comedia del siglo de oro porque se compromete con la estructura significante de otras, sin que importe que la realidad no sea exactamente así. En esos contextos, podremos considerar "realista" cierto detalle que, partiendo del respeto del sistema y los elementos propios de uno de esos códigos, suponga una novedad por razones de parecido con lo que entendemos por realidad.

Por su parte, la credibilidad de un autor o un texto depende de sus características intrínsecas tanto como de su anclaje: la editorial o la serie en que aparezca, el aparato crítico con sus referencias parcialmente conocidas, las autoridades convocadas o las que lo defienden en otros textos, la adecuación de los acontecimientos reflejados con nuestro conocimiento de lo real, etc.

Puesto que esos anclajes pueden resultar falsos, el código permite mentir: Max Aub utiliza el sistema propio de las investigaciones sobre arte para inventar la identidad 
de un pintor cubista ficticio, Jusep Torres Campalans, y manipular un entorno real. La adecuación y coherencia de su sistema de anclajes permitieron que la historia se diera por cierta en su momento. Lo mismo pasó con algunos fraudes famosos (Guevara, Macpherson, Chatterton, Clifford Irving, etc.).

Por último, la verdad en un texto puede establecerse contrastándolo con otros documentos del tipo que sea (textuales, arqueológicos, etc.). Solo ahí se descubren algunos fraudes ( $y$ otros pasan desapercibidos, para convertirse en falsas evidencias para terceros): sabemos que algunas famosas obras de arte son en realidad imitaciones, que incluso podrían estar sirviendo para establecer los criterios de identificación y certificación de otras obras de arte en relación con sus falsos autores; sabemos que algunos importantes autores de la historia de la literatura utilizaron "negros", y que es imposible separar con claridad la huella de las personas físicas en el texto literario.

Pero las exigencias de la comunidad científica en relación a lo que puede ser considerado verdadero son también muy variables (como lo es la fiabilidad de los aparatos críticos empleados). En ningún caso hay que considerar universal el empeño actual por identificar los nombres propios tras las obras conservadas.

\section{LAS TRANSFORMACIONES DEL RELATO}

En torno a la evolución caprichosa y voluble de estos conceptos en la historia de los códigos literarios, la aparición de las convenciones propias de la ficción narrativa nos enseña ciertos mecanismos repetidos, que nos permiten aventurar estas fases: innovación, generalización, aburrimiento, parodia, olvido y redescubrimiento o falsa novedad. En principio, todo posible rasgo literario es susceptible de estudio desde esta perspectiva (el octosílabo, las unidades aristotélicas, la figura del detective privado, etc.) y también en otras artes (el sfumatto, la perspectiva, el escorzo, etc.). Solo como ejemplo nos limitamos a las convenciones de la ficcionalidad en los orígenes de la novela en España, Francia e Inglaterra: se trata de códigos relativamente aislados y sujetos a modificaciones relativamente particulares (de hecho el éxito de estos fenómenos en esos tres países no siempre coincide en el tiempo, sin que haya que hablar necesariamente de influencia: en Inglaterra es posterior, pero su desarrollo es claramente autónomo, a partir de las circunstancias particulares de un determinado momento de su cultura).

\subsection{INNOVACIONES}

Lo imprevisto es parte consustancial de cualquier comunicación, que requiere para su eficacia un equilibrio determinado entre redundancia y novedad (como muestra la teoría de la información). Pero las novedades que aparecen en un mensaje dejan huella 
en la memoria de sus receptores y tienen un efecto sobre la constitución misma del código, que se ve distorsionada en mayor o menor medida, según una relación entre la novedad y su pertinencia. El código tiene un enorme grado de flexibilidad (recupera su forma tras los mensajes) pero también tiene indudablemente cierta plasticidad: acoge y se reordena a partir de las novedades. En la novela, cuando un autor introduce en determinada tradición una idea original (o importada a partir de otra tradición, o retocada y con características originales, etc.), provoca una reacción en el público y los autores sucesivos, que ya no pueden enfrentarse al género de la misma manera. Así, Angelet (1999: XXXV-XXXVI) explica la parodia que hace Rabelais de las Illustrations de Gaule et singularités de Troie (1511) de Jean Lemaire de Belges, que seguía la tradición virgiliana al reclamar un origen troyano para la dinastía real francesa: en Pantagruel (1534) se imita este recurso para fundamentar los orígenes de una familia de gigantes descaradamente fabulosos, en una utilización incuestionablemente paródica del recurso de citar fuentes inventadas.

Pero naturalmente, la literatura científica utiliza las fuentes con otra lógica. En el discurso escrito, las citas se utilizan normalmente para hacer referencia a fuentes reales (aunque siempre debería haber un grado de desconfianza en toda cita y en todo argumento de autoridad): Herodoto cita inscripciones públicas y poetas (Simónides, etc.); Polibio cita a Filino y Fabio, que trataron antes que él los acontecimientos ocurridos durante las Guerras Púnicas. Platón transcribe lo dicho por Sócrates, y Aristóteles es la fuente principal por la que conocemos a los presocráticos. De varias novelas griegas solo se conserva el resumen en los Epítomes de Focio: las Babiloníacas de Jámblico, las Maravillas de más allá de Tule de Antonio Diógenes y el libro de viajes Sobre la India de Ctesias de Cnido. Estos textos son obras escritas de buena fe (si la historiografía al respecto no se engaña) según el principio del "manuscrito encontrado" en la modalidad de la refundición y manipulación para hacerlo más interesante o cómodo.

Pronto aparecen obras que trataban de convencer efectivamente de algo que era una superchería (como la de Geoffrey de Monmouth, que finge fraudulentamente copiar un texto histórico que incluye la historia del rey Arturo, o Dares y Dictis, supuestos testigos de la guerra de Troya, etc.), aunque no siempre es fácil saber en qué medida creían en esas fuentes apócrifas los diversos autores que las citan. El libro del Caballero Zifar también recurre a cierto "trasladador de la estoria que adelante oyredes, que fue trasladada de caldeo en latin e de latin en romance" (Anónimo, 1993: 70).

Como dice Angelet (1999: XLVII) del manuscrito encontrado, "à la fois procédé de véridiction et protocole d'attestation, il est inséparable de la citation. II consiste à invoquer le témoignage d'autrui comme fondement de la certitude. [...] Comme tel, le 
manuscrit trouvé est une variante de l'argument d'autorité"1. Pero el topos literario se basa en la imitación de un procedimiento de cita real y que solo puede distinguirse de las citas ficticias comprobando sus referentes. Cualquier autobiografía real puede incluir un prólogo verídico en el que un editor real explica las circunstancias de su trabajo con el manuscrito que verdaderamente ha escrito otro individuo real, el autor. Por ejemplo, el Diario de un genio, realmente escrito por Dalí, está precedido por una introducción que sigue la más pura tradición novelesca; la correspondencia de Zweig con Freud, Rilke y Schnitzler está igualmente publicada bajo la responsabilidad de determinados editores que han escogido y ordenado de entre la enorme masa de cartas aquellas que pueden tener más interés para el lector actual.

De modo que la diferencia entre la historia, con los mecanismos y garantías que permiten al investigador rastrear las fuentes documentales, y la utilización de los mismos con la finalidad de engañar, de generar un ambiente verosímil para el relato de sucesos inventados, no puede encontrarse en última instancia dentro de los textos que pretendemos juzgar, sino en otros textos a los cuales estos se refieren.

La novedad que encontramos en Amadís de Gaula (1508) es la utilización de ese recurso justificativo excesivo para un libro que no pretendía pasar por verdadero: Montalvo declara haber refundido los tres primeros libros ya existentes (y que la crítica actual cree reales) y haberles añadido el cuarto y las Sergas de Esplandián,

\section{[...] que hasta aquí no es en memoria de ninguno ser visto, que por gran} dicha paresció en una tumba de piedra, que debaxo de la tierra en una hermita, cerca de Constantinopla fue hallada, y traído por un úngaro mercadero a estas partes de España, en letra y pergamino tan antiguo, que con mucho trabajo se pudo leer por aquellos que la lengua sabían; en los cuales cinco libros como quiera que hasta aquí más por patrañas que por crónicas eran tenidos, son con las tales enmiendas acompañados de tales enxemplos y doctrinas que con justa causa se podrán comparar a los livianos y febles saleros de corcho, que con tiras de oro y de plata son encarcelados y guarnescidos, porque assí los cavalleros mancebos como los más ancianos hallen en ellos lo que a cada uno conviene (Rodríguez de Montalvo, 2001: 224-225).

Aunque el enunciador de este prólogo asevera haber "pulido" un texto traducido del griego ( $y$ en eso se inserta claramente en la moda humanista de su tiempo), reconoce inmediatamente que todo el mundo considera sus originales meras "patrañas", pero

1 [a un tiempo procedimiento de veridicción y protocolo de certificación, es inseparable de la citación. Consiste en invocar el testimonio ajeno como fundamento de la certidumbre. [...] En ese sentido, el manuscrito encontrado es una variante del argumento de autoridad]. 
está seguro de que incluso como tales podrán tener una utilidad por su ejemplaridad. Considera secundario el valor de verdad de su historia, es decir que empieza su libro solicitando al lector que deponga su escepticismo, condición fundamental de lo que hoy se considera "ficción".

En su propia tradición, esto mismo viene a ser válido para Rabelais, que utiliza de manera evidentemente paródica un procedimiento que hasta entonces solo podía usarse con valores de verdad o con intenciones abiertamente fraudulentas. La parodia no participa de la oposición 'verdadero/falso' porque provoca un desplazamiento en su sentido, que ya no estará tanto en lo que significa como en la pertinencia o parecido con el enunciador del texto parodiado.

La imprenta facilitó la difusión de esta novedad que fue capaz de desestabilizar el equilibrio entre verdad, credibilidad y verosimilitud a principios del siglo xvi: en la Edad Media hay fuentes más o menos inventadas o apócrifas, y aparecen menciones a manuscritos, pero la versión más pura del topos consiste en editar (o fingir editar) e imprimir un manuscrito encontrado, como se hace desde los tiempos de Poggio Bracciolini; eso es lo que imita Montalvo en su Amadís; eso es lo que falsificó en varias ocasiones Fray Antonio de Guevara, "el obispo de Mondoñedo" famoso por la tranquilidad con la que inventaba fuentes cuando no disponía de las verdaderas, que se justifica diciendo en el "Argumento" del Libro áureo: "Pienso de esta historia tienen muy pocos notiçia, porque hasta agora no la avemos visto impressa" (Guevara, 1993: 19).

Otro fraude que supo aprovechar las complejidades literarias de la falacia referencial fue el Lazarillo de Tormes (1554), que pasó por una autobiografía real, gracias a la carencia de una autoría reconocida, pero sobre todo por el desarrollado realismo que consigue con tantas referencias actuales y por la inserción de la trama en una situación muy elaborada en el prólogo y la conclusión de la obra. Como dice Rico (1998:29-30), "el lector de la época [...] tendería a tomar al libro al pie de la letra y a entenderlo como escrito efectivamente por un Lázaro de Tormes de carne y hueso; el propio autor jugaba a ese juego en una medida harto mayor que cualquier novelista del siglo XIX". Fundamentalmente, se hizo público y difundió premeditadamente eludiendo cualquier marca de género que permitiera a los lectores identificarlo como literario, "el verso, los géneros establecidos, los temas consagrados... [...]. En tal sentido, realcémoslo, el Lazarillo era un fraude: no un relato que inmediatamente pudiera reconocerse como ficticio, sino una falsificación, la simulación engañosa de un texto real, de la carta verdadera de un Lázaro de Tormes de carne y hueso" (Rico, 2000: 165). 


\subsection{GENERALIZACIÓN}

A partir de la sorpresa inicial, el recurso pasa a la memoria de los receptores, con lo que se constituye en uno más de los elementos integrantes del código. A partir de ese momento, puede repetirse y generalizarse, llegando a más receptores y prestándose ya para la imitación por parte de nuevos escritores que lo consideren modelo digno.

Ejemplarmente, el recurso al manuscrito encontrado triunfa en los libros de caballerías en la imitación del uso que le dio Montalvo: Florisando (1510), Lisuarte de Grecia (1514), etc., repiten convencionalmente el procedimiento. Del mismo modo, también en Francia se suceden los manuscritos encontrados según múltiples variantes, sin dejar de existir, naturalmente, un uso fraudulento, como el que se da en Du vray et parfait amour, escrit en grec par Athénagoras, philosophe athénien, contenant les amours honestes de Théogènes et de Charide, de Phérécides et de Mélangénie (1599), de Martin Fumée.

Pero si en ese proceso deja de sorprender, puede convertirse precisamente en una lanzadera para nuevas sorpresas. En esta nueva fase del sistema, la novedad se encuentra en la forma particular de utilizar un método ya conocido.

Con el gran éxito de difusión que tuvo el Lazarillo, no cabe duda de que se convirtió rápidamente en un modelo en la cultura del momento, incluyéndose referencias de todo tipo en textos literarios, pictóricos, etc. En esa nueva situación pasaba a ser posible para un autor español inventar una historia similar, es decir, una autobiografía ficticia, que ya presentara esos rasgos caracterizadores que permitirían a cualquier lector reconocerla como tal. Cuando Mateo Alemán publicó su Guzmán de Alfarache (1599) ya estaba prácticamente garantizado que cualquier lector reconocería el modelo del Lazarillo y que sabría entender la dualidad autorial entre el prólogo, en que Alemán no esconde ser el verdadero autor del libro, y los capítulos, que aparecen atribuidos al protagonista.

Puede entenderse que Alemán no trató de copiar el modelo, puesto que en ningún caso pretende hacer pasar por verdadera la vida relatada por su personaje, sino que propone recoger las coordenadas que había establecido aquel para a partir de ellas desarrollar una nueva historia, con unas intenciones bien diferentes. El Lazarillo podía ser un engaño, pero el Guzmán ya era ficción, un relato cuyo interés no radicaba en su posible anclaje referencial sino en otros aspectos, en su verosimilitud, en la moral que ayuda a ejemplificar, en la invención de situaciones y caracteres, etc. En resumen, propone una interpretación de la vida (no por casualidad la continuación de 1604 se subtitula "Atalaya de la vida humana") que no se somete a condiciones de verdad.

Con la recuperación del patrón del Lazarillo, que se atreve a centrarse de manera verosímil en un personaje inventado de clase baja, el Guzmán establece en las memorias de sus lectores un nuevo conjunto de propuestas que se convierte a su vez en el modelo a imitar por otros autores, lo que dará origen al Ilamado género "picaresco". 
Entre los muchos otros ejemplos posibles de obras que han aprovechado una novedad anterior para a su vez proponer ramificaciones, podemos señalar el caso de Pamela (1740), novela que utilizaba el recurso ya ampliamente utilizado del intercambio epistolar pero supo encontrar un hilo argumental complejo y capaz de atrapar a los lectores con una trama sentimental y un problema moral. La novedad de su propuesta ha eclipsado sus antecedentes, entre los que se encuentran las Lettres portugaises de Guilleragues en 1669 (Kany, 1937).

La generalización de un procedimiento puede llevar a la multiplicación de sus variantes, pero también es posible que simplemente pase a convertirse en un parámetro nuclear de su género o de un nuevo género. Es indudable que el manuscrito encontrado estuvo cerca de volverse clave de la ficción, pero no se estabilizó en esa posición porque (en las tradiciones que estamos considerando) pronto resultó redundante y dio paso a nuevas ficciones en las que no era necesario. En cambio, la propia idea de ficción, lo que Rico (2000: 173-174) llama "el milagro de la narración sin narrador", se alcanzó progresivamente durante el siglo XVIII en Francia e Inglaterra fundamentalmente y se convirtió en piedra angular de la literatura occidental en el XIX, posición que todavía hoy detenta pese a cambios en otros aspectos del código.

En otros géneros también encontramos invenciones estelares que se vuelven canónicas, como las que definen el teatro barroco español desde la generación de Lope de Vega o las propuestas métricas de Dante y Petrarca. La invención de la perspectiva es un ejemplo válido para la historia del arte, y la tonalidad puede serlo para la de la música: pese a las transformaciones sufridas, ese principio se mantiene en el centro de la composición musical desde el primer Barroco.

\subsection{CANSANCIO Y PARODIA}

Naturalmente, el siguiente paso posible en la historia de un procedimiento literario es el hastío: se generaliza hasta un punto que se vuelve completamente predecible, y provoca la repulsión de los críticos (aunque las clases más populares no siempre son tan exigentes). Esto es particularmente habitual cuando la idea no ha sido tan interesante como para provocar respuestas y variantes o como para convertirse en el patrón a partir del cual innovar, pero incluso en el caso de un recurso tan fértil como el del manuscrito encontrado llegan épocas de cansancio, cuando los testimonios en su contra se multiplican.

Así, la narrativa epistolar, que tanto éxito alcanzó a partir de Pamela, entró en decadencia en Inglaterra a finales del XVIII, en la misma época en que aburría el manuscrito encontrado en Francia. Es cierto que la verosimilitud del método exigía una serie de coartadas que no era plausible que se dieran tan a menudo como exigía 
el mercado editorial, pero más allá de las razones que puedan encontrarse para atacar o defender el juego, lo que esos ataques ponen de manifiesto es la propia naturaleza efímera de las modas.

Probablemente, en una situación literaria como la inglesa hacia 1700, donde no había un código de la ficción capaz de dar cabida a nada que no participara de la condición de lo verificable, la invención y suplantación de las identidades de esos personajes-autores de cartas era inicialmente un recurso necesario. Sin él, pocos habrían aceptado leer un libro lleno de falsedades. Pero cuando el público se adaptó a esta posibilidad, cuando empezó a reconocer los rasgos de la ficción en el momento de levantar la portada de un libro (y a aceptar suspender su incredulidad), esas técnicas y coartadas del novelista se volvieron superfluas.

Efectivamente, los detractores del método se oponen a artificios que resultan redundantes. Como diría Balzac mucho más tarde, "si se está decidido a subir a las tablas, hay que decidirse, por cierto, a hacer de charlatán, pero sin ayuda de maniquí" (en Les Chouaus, recogido por Tacca, 1973: 47). El procedimiento de proclamar la veracidad literal va siendo sustituido por maneras de contar más atentas a la probabilidad de lo contado y de la manera de contarlo, con el objetivo cada vez más claro de alcanzar "el milagro de la narración sin narrador".

Las excusas para la narración se convierten entonces en objeto de parodia y sarcasmo, cuando no de ataque frontal. En el ámbito hispánico, es paradigmática la perspectiva irónica que da Cervantes a su uso de la técnica del manuscrito encontrado al emplear de forma voluntariamente inverosímil un recurso que se originó para dar verosimilitud. Su Cide Hamete Benengeli es un divertido intermediario poco veraz e irreconciliablemente "antiguo" para una narración ambientada en un presente reconocible para cualquiera.

Menos escrúpulos tiene Scudéry cuando declara, en el prólogo "au lecteur" de Artamène ou le Grand Cyrus, que rechaza toda trampa y excusa a la hora de enfrentarse a un tema abiertamente inventado por ella misma:

[...] après tout, c'est une Fable que je compose, et non pas une Histoire que j'écris. Que si cette raison ne satisfait pas pleinement les scrupuleux, ils nont qu'à s'imaginer pour se mettre l'esprit en repos que mon Ouvrage est tiré d'un vieux Manuscrit Grec d'Hégésippe qui est dans la Bibliothèque Vaticane, mais si précieux et si rare qu'il n'a jamais été imprimé et ne le sera jamais (Scudéry)².

2 [después de todo, es una fábula que yo compongo, y no una historia que escribo. Y si esta razón no satisface plenamente a los escrupulosos, para tranquilizar su espíritu estos solo tienen que imaginar que mi obra está sacada de un viejo manuscrito griego de Hegesipo que se encuentra en la Biblioteca Vaticana, pero tan precioso y raro que nunca ha sido impreso ni lo será jamás]. 


\subsection{OLVIDO}

El código puede variar también por la desaparición paulatina de alguno de sus elementos. La respuesta definitiva al aburrimiento causado por la repetición excesiva de un recurso, un topos o una técnica no es otro que el desinterés, la escasez de nuevos textos en que aparezca. El desuso es también una transformación del código, cuyo responsable es más bien colectivo que individual: todos aquellos autores que deciden no emplear ese recurso (o emplearlo de una forma nueva o diferente) están participando en el cambio. Puede llegar un momento en que los lectores definitivamente lo desconozcan.

Los procedimientos propios del relato picaresco van desapareciendo hasta el punto de que son totalmente ajenos a la España de mediados del siglo XVIII. También los libros de caballerías quedaron en segundo término tras la lectura del Quijote, de manera que este perdió en gran medida su sentido original de parodia, situación en la que sigue encontrándose hoy, toda vez que la inmensa mayoría de los lectores que se enfrentan al texto cervantino ignoran completamente el género parodiado. Si conserva su interés después del colapso definitivo del género caballeresco es quizá porque algunos de sus rasgos perviven en otros géneros populares.

\subsection{REINVENCIÓN}

El olvido de un determinado recurso puede dar lugar a una nueva situación (un nuevo estadio del código) en la que vuelva a ser posible que alguien innove con la vieja idea, sea por pura ignorancia de lo que le precede o bien con plena consciencia de estar restaurando algo que ya se había usado. Como el papel se conserva, siempre es posible la lectura de un texto antiguo, obsoleto y pasado de moda, de modo que siempre se puede redescubrir un clásico olvidado para desempolvar un viejo truco. Tal vez eso es lo que hacía Walter Scott cuando lograba que sus lectores llegasen a dudar de que se tratase verdaderamente de una ficción y no, como aseguraba el autor en algunos prólogos, de un documento histórico.

Por supuesto, nunca se da la situación de que todos los lectores compartan exactamente la lista de sus lecturas, de manera que lo que para unos es novedad no pasa de ser para otros un gastado tópico. Pero sí parece posible comprender como código del momento ese conjunto de lo que está en boca de todos en un momento dado, un núcleo de grandes éxitos rodeado por afueras de intereses particulares y textos que van entrando en el olvido.

De hecho, la posibilidad de que un autor tenga éxito como innovador mediante el recurso a procedimientos de segunda mano es la prueba de que el código en un determinado momento ya no es igual que antes. La sorpresa de un público que saluda o rechaza lo que cree una novedad demuestra su olvido. 
La recuperación de una idea gastada puede llevarse a cabo con enfoques más o menos novedosos, de manera que efectivamente constituyan una novedad. El caso de Scott es seguramente ese, puesto que aprovechó el recurso del manuscrito encontrado con la idea de recrear momentos del pasado lejano desde una perspectiva historicista que era fundamentalmente nueva: recuperados de entre crónicas y archivos ficticios, esos testimonios eran capaces de restaurar los tiempos heroicos desde el punto de vista de la vida privada.

También es posible que un autor preste atención a cierto recurso en un momento en que no ha desaparecido por completo, es decir, que lo haga con la clara intención de generar un contraste entre la manera en que su público recuerda el tópico y la manera nueva que él propone, lo cual puede hacerse con intenciones estilísticas complejas que recorren todo el espectro que va de la parodia al homenaje: si el uso por Cervantes de la técnica del manuscrito encontrado era paródico, el de Eco en El nombre de la rosa es un homenaje: "naturalmente, un manoscritto".

\section{DESARROLLOS DESINCRONIZADOS}

Es necesario considerar no solo las variaciones que se dan en los códigos con el paso del tiempo (diacrónicas) sino también las diferencias que se dan entre sus manifestaciones en distintos lugares (diatópicas), incluyendo tradiciones o culturas diversas que unas veces se acercan más a los códigos de algunos de sus vecinos o a los de otros y otras parecen complacerse en alimentarse solo de sus propios antepasados.

Podemos recurrir a las mismas fases de la vida de un recurso para comparar la cronología que les corresponde en dos o más tradiciones diferentes. Aunque conectadas por traducciones y por una historia de relaciones internacionales común, las literaturas inglesa, francesa y española estaban separadas sobre todo por el uso de lenguas diferentes, lo que sin duda dificultó la valoración de las novedades surgidas en un código vecino. A diferencia de épocas posteriores, cuando el volumen de las publicaciones y de las traducciones alcanzó niveles muy superiores (a partir sobre todo del siglo xix), el conocimiento de las literaturas vecinas en la Edad Moderna se limitaba a algunos textos especialmente exitosos, que se leían fuera de contexto y se apreciaban a veces por razones diferentes de las de sus países de origen. En esa situación, no es de extrañar que la vida de un recurso determinado siguiera en cada tradición un desarrollo cronológico bien diferenciado.

El topos del manuscrito encontrado, por ejemplo, se desarrolla en fases cronológicamente muy diferenciadas en la tradición española y en la inglesa. Ya hemos visto que se trata de un recurso antiguo basado en la cita de documentos en textos históricos o en fraudes, y que da lugar a un aprovechamiento estrictamente literario en 
torno a 1500 de la mano de los primeros autores de libros de caballerías que juegan a unir la vieja autoridad del libro con la moda de la recuperación de textos griegos en bibliotecas. Su generalización durante el siglo XVI desemboca en la burla de Cervantes en el Quijote, que le da un nuevo sentido polifónico y contradictorio. Eso era posible porque el público empezaba a estar harto de esa convención demasiado repetida: aparece en Amadís de Gaula, Tirante el Blanco, Lepolemo, Don Belianís de Grecia, Crónica de Floriel de Niquea, Cirongilio de Tracia...

Sin embargo, quizás como consecuencia precisamente de la sátira establecida por Cervantes, el recurso retrocede durante el resto del siglo XVII y el XVIII, olvidado y proscrito de la mayoría de los textos, hasta el punto de que Nicolás Pérez en su El Antiquixote no era dueño del código necesario para entender esa sátira, es decir que no conocía aquellos antecedentes de los que se burlaba Cervantes y que justificaban por la parodia sus incoherencias. Pérez critica el final de la primera parte del Quijote porque se toma al pie de la letra las afirmaciones del narrador sobre el descubrimiento azaroso de una caja de plomo con los papeles de la continuación de la historia (Pérez, 1805: 19-22), lo cual está en flagrante contradicción con otros puntos de la historia en que el narrador atribuye otros orígenes a su relato, así como con la época en que se usaron en España los caracteres góticos a los que Cervantes alude, etc. Obviamente, al crítico neoclásico no le importa mucho la posibilidad de que todas esas contradicciones puedan ser conscientes (y sarcásticas). Para él son un defecto imperdonable porque trata de asimilar el Quijote al código clasicista o a las exigencias de la Historia, cuya verosimilitud debería imitar todo relato, pero sobre todo porque ignora los recursos propios del género caballeresco del que se burla Cervantes.

El recurso del transcriptor tendría que volver a España como una novedad extranjera, en las traducciones de las novelas inglesas y francesas del siglo xviii (como la de Pamela en 1794 o la de las Cartas persianas en 1821) o en el Cadalso en las Cartas marruecas (1782).

La situación cultural en Inglaterra en el siglo XVII era muy diferente. Aunque se tradujeron novelas extranjeras (Don Quijote desde 1612, Guzmán de Alfarache en 1622), parece que las restricciones morales de los años puritanos coartaron el desarrollo de la ficción durante bastante tiempo con toda su literatura moral. Como desarrolla Millet (2007), las primeras obras de ficción inglesas (aparte de las oníricas y alegóricas como The pilgrim's progress, de 1678) aparecen bajo la coartada del narrador-testigo: en Oroonoco (1688), de Aphra Behn, el enunciador, que se identifica con la autora y también con la narradora de la historia del príncipe homónimo, sostiene que es verídico todo lo que se cuenta (y la crítica actual no ha podido demostrar lo contrario). Esta posición al borde mismo del fraude se desliza hasta caer en él en An Historical and Geographical Description of Formosa, an Island subject to the Emperor of Japan (1704), de George Psalmanazar, que 
pasaba por ser una descripción real de Formosa cuando su autor, que fingía haber nacido allí, en realidad jamás había pisado esa isla.

Poco a poco, este recurso al testimonio fingido deja paso a historias pretendidamente editadas por quien en realidad es el autor, lo que ya es una utilización del topos del manuscrito encontrado. Tras la traducción de la Histoire de Sévarambes de Denis Vairasse, los primeros ejemplos son de esa misma época: las Love letters between a Gentleman and his Sister (1684-87) de Aphra Behn. Pero el recurso alcanza su madurez con las imposturas de Defoe, que presenta Robinson Crusoe (1719) y Moll Flanders (1722) como autobiografías, fingiendo en los prólogos ser solo editor del relato. No es fácil decir si se trata todavía de fraudes o ya se parte de la idea de ficción como suspensión de la incredulidad: acaso el libro fuera simultáneamente un engaño para los lectores ingenuos y una ficción para los que conocían algunos antecedentes de otras literaturas.

Esos primeros autores necesitaron coartadas porque partían de un código en el que no era aceptable la invención de historias sin una buena excusa. Todavía Swift, en un prólogo que no se atreve a firmar, finge que ha encontrado y solo es editor de los Gulliver's travels $(1723,1735)$, libro que indignó a un lector incrédulo, quien “lo arrojó a un lado enfadado y declarando en voz alta que no creía una palabra de lo que allí aparecía escrito" (Eagleton, 2009: 58). Obviamente, ese lector ingenuo no compartía el código de la ficción y admitía las patrañas de Psalmanazar o Defoe, objeto de las burlas de Swift.

Progresivamente fue haciéndose posible contar sin más una historia inventada. Las técnicas de coartada tuvieron inicialmente la función de declinar la responsabilidad del autor sobre la verdad de un texto ante una sociedad que no había asimilado la posibilidad de la ficción literaria, pero una vez que el código fue dando por supuesta la suspensión provisional de la incredulidad en los lectores de novelas, pasó a resultar una excusa redundante. Una vez que el código se institucionaliza, ya no es, como supone Herman (1998: 114), que el autor quiera engañar con una fuente verosímil para llevar al lector a creer que efectivamente lo que cuenta es verdad (como encontramos en el Lazarillo o Psalmanazar), sino que simplemente se preparaba una salida por la puerta de atrás para el caso de que alguien lo llamase mentiroso. En la nueva situación, a medida que los lectores se avenían a creerse lo que les contaban, la verosimilitud lograda por medio de los falsos documentos fue perdiendo su función original y solo era un estorbo, de ahí su paulatina desaparición. Lo que podía ser inaceptable o innecesario para los ingleses de principios del siglo xvii se fue haciendo probable durante la segunda mitad.

Consecuentemente, la invención de detalles anecdóticos o irrelevantes para la historia era inicialmente indigna (es llamativa su práctica ausencia en Defoe, por ejemplo, así como lo era también en Montalvo o Mme. de Lafayette) y se fue volviendo necesaria (como en Austen). 
En resumen, para 1800, época en que en España Cervantes vivía el punto álgido de una incomprensión que derivaba del olvido del código en que se situó su Don Quijote, en Inglaterra otro código que admitía muchos de los mismos recursos posibilitaba que fuera ampliamente admirado. Mientras en España el manuscrito encontrado se había retirado de escena desde principios del siglo XVII, en Inglaterra aparecía solo a finales de ese siglo.

Por otro lado, aunque Cervantes y la picaresca fueron ampliamente apreciados por los autores ingleses del siglo XVIII, no puede limitarse el desarrollo de la novela en ese país a una consecuencia de esas traducciones, sino que responde a unas motivaciones particulares, que después sintonizan con los modelos españoles. De modo inverso, la recuperación española de esas ideas estéticas y literarias se deberá sobre todo a la traducción posterior de los autores ingleses que las admiraban.

Podría entenderse entonces la historia del recurso como un entrar y salir del foco del código de la mano de los escritores, unas veces como consecuencia de propuestas espontáneas, otras a partir de influencias extranjeras o de la recuperación de textos olvidados.

\section{HISTORIA, FRAUDE, PARODIA}

No puede entenderse toda la literatura con un criterio sincrónico, como si hubiera sido concebida por una mente universal. Los códigos cambian, así que los ajustes son diferentes en cada momento. Por eso no podemos creer (como sostiene Herman, 1998: 105) que todo lector, en el siglo XII como en el XVIII, entiende el manuscrito encontrado como un recurso de la ficción, aunque sin duda es cierto que en determinadas codificaciones de la ficción, en momentos específicos de algunas tradiciones literarias concretas, "la formule, indéfiniment variée: 'j'ai eu la chance de mettre la main sur le document autographe que voici' signifiait'voici un roman dont je suis l'auteur'"'3 (Angelet, 2003: 12), o sea que la mera presencia del paratexto que explica la accidental aparición del manuscrito era sin duda un denotador de ficción.

Tampoco podemos perder de vista que algunas de esas obras que recurren a fuentes inventadas no están jugando con el lector, sino que están tratando de engañarlo: el fraude se pasea por la historia de la literatura, desde Geoffrey de Monmouth hasta el presente, pasando por Guevara, el Lazarillo, etc. Parece que la historiografía literaria prefiere elevar algunos fraudes a la categoría de ficción y a la gloria literaria mientras otros son condenados por criterios morales y quedan relegados a los almacenes de curiosidades.

3 [la fórmula, indefinidamente variada, "he tenido la suerte de echar mano a este documento autógrafo que aquí ofrezco" significaba "he aquí una novela de la que soy el autor"]. 
Obviamente, algo que en una época es capaz de engañar puede convertirse en otra en un divertido juego. Los recursos de la autobiografía del ahistórico Lázaro de Tormes admiten imitación; las transcripciones y traducciones verídicas pasan a ser objeto de fraude (como en Guevara o Macpherson) y por último de juego literario (Amadís).

Es llamativo que en las tres literaturas contempladas haya antecedentes fraudulentos inmediatos para los primeros casos claros de ficción, que constituyen parodias del engaño o que se aprovechan del territorio conquistado por los impostores: Rabelais parodia a Belges, Montalvo exagera el topos, Alemán aprovecha la estructura del Lazarillo, Swift satiriza a Defoe y a Psalmanazar. Incluso puede que sea posible fundamentar un paralelo evidente con la novela griega, que se desarrolla a partir de Luciano de Samósata, autor que satirizaba las increíbles aventuras narradas en algunos libros de viajes claramente fraudulentos (como Sobre la India). Aunque las fechas y las líneas de influencia son en el contexto helenístico mucho más difíciles de establecer.

Y es que el concepto de fraude no tiene unos límites precisos, y puede definirse como "any text whose actual provenance differs from what it is made out to be"4 (Ruthven, 2001: 39). Este especialista en el fraude literario desconfía del criterio centrado en las intenciones del autor, por cuanto no están a nuestro alcance y pueden ser objeto de otro fraude más. Contesta así a esos otros críticos que las consideran cruciales a la hora de distinguir y definir la diferencia entre "hoax" y "forgery", o entre "falso" (falsificación voluntaria e interesada), "plagio" (utilización consciente e interesada de materiales ajenos), "espurio" (interpolación voluntaria pero desinteresada en un texto ajeno), "impostura" (atribución falsa, consciente pero desinteresada por razones de prestigio u homenaje), "falsario de ficción" (engaño con interés intelectual) y "pseudoepigráfico" (error filológico en la atribución) (Guzmán Guerra, 2011: 26-29).

Es muy posible que, situados en la atalaya del presente y cegados por las ideas de identidad y propiedad, el rasero que realmente imponemos a todos esos textos limítrofes sea fundamentalmente estético y afectivo: aquellas obras que han conseguido captar nuestra simpatía escapan a las denominaciones denigrantes (así el Lazarillo o Defoe), mientras que las que perdieron todo su valor cuando se reconoció públicamente su falta de anclaje han sido relegadas al olvido. Tanto Lázaro de Tormes como Robinson Crusoe planteaban asuntos y modos de ver el mundo que trascendían los problemas de la credibilidad. Una vez descubierto que nunca hubo personas reales tras esos nombres y sus relatos, los textos mantuvieron su interés por otras razones. Contrariamente, la falsedad de la descripción de Formosa eliminó todo el interés que podía haber tenido ese texto.

4 [cualquier texto cuya verdadera procedencia sea diferente de la que aparenta tener]. 
Por eso, y admitiendo que la clasificación de Guzmán Guerra es incuestionablemente útil, tal vez sea mejor buscar las diferencias por razones del código en que se mueve cada autor. Un mismo hecho puede cambiar de categoría según la tradición en la que se mueva: pasar de homenaje a plagio o viceversa, etc. Las intenciones del autor no son solo (como cree Ruthven, 2001: 39) una cuestión psicológica, la de sus "motivos inescrutables", sino que se insertan en el lenguaje de sus contemporáneos.

Podemos volver a lo dicho al principio: las relaciones entre verosimilitud, credibilidad y verdad dependen del código en que aparezcan: los valores imitados o copiados, plagiados o falsamente atribuidos, pueden ser los mismos o diferentes, centrales o sin importancia, en épocas diferentes; la identidad del autor es crucial solo en algunos enclaves espaciotemporales; la utilización de una trama de una obra literaria anterior no siempre ha sido un plagio; la atribución de una obra a otro autor tampoco ha sido siempre un crimen: podemos recordar casos de autores semi-míticos con listas enormes de textos atribuidos, como Pitágoras, y oponerlos a la indignación de esos autores modernos (como Calderón) que publican su obra solo para contrarrestar las ediciones espurias.

\section{CONCLUSIONES}

Las transformaciones en el código no son una evolución unidireccional, unívoca y lineal (como querían los positivistas), sino las progresiones balbucientes de varios códigos que se entrecruzan. Hay cambios múltiples en las afueras de los códigos y menos y más lentas en su núcleo. Dentro de cada tradición como sistema, se avanza a partir del estadio anterior, en el cual se introduce la intervención que es capaz de desplazar en mayor o menor medida el equilibrio. En resumen, no se da el progreso, sino avances parciales que mantienen el conjunto en una posición más o menos estable.

Es por esas razones por las que la historia de la literatura puede servir de ejemplo para entender el funcionamiento de otros códigos. Una intervención individual (sea un libro o una palabra o un gesto o un whats-app, etc.), lo mismo que un silencio, participan en la conformación de cualquier estadio posterior de un código. Naturalmente, si el propio estudio de las transformaciones de la ficción está lejos de la sencillez (y convendría un análisis más pormenorizado de las tradiciones involucradas en su configuración para poder entender los procedimientos realmente imitados y el alcance de cada innovación), otros códigos más volubles y múltiples se pierden en un grado de complejidad que solo puede ser tratado por procedimientos estadísticos. Como el uso no registrado de cada hablante participa en el cambio lingüístico, solo por procedimientos aproximativos pueden llegar a entenderse las razones del cambio o la identidad social de sus principales impulsores. 
Algo parecido ocurre con la literatura de nuestro tiempo. Ya no es posible estar al día del conjunto de textos publicados dentro de una tradición concreta. Los códigos que derivan de las nuevas tecnologías resultan infinitamente más difíciles de estudiar que los que se basan en las posibilidades editoriales de la Edad Moderna. La misma velocidad de los avances tecnológicos que los posibilitan está ya fuera de lo que un individuo puede asimilar, así que las aportaciones a las modas estéticas cibernéticas superan las capacidades de estudio de cualquiera; los participantes en las transformaciones de esos códigos son ya tan difíciles de rastrear como los hablantes olvidados de una lengua.

Además, el progreso tecnológico permite un conocimiento mucho más amplio de múltiples tradiciones simultáneas, con lo que eso que en la modernidad constituía culturas literarias bien diferenciadas (la tradición francesa, la inglesa, la española, etc.) no es hoy más que una mezcla plurilingüe, un todo complejo pero comunicado. Una gran parte de la población es capaz de leer en varios idiomas, y estar así al tanto de las novedades que aparecen en otras lenguas, que a veces le interesan más que lo que ocurre en su propio país y región. El mercado impone un núcleo literario a los códigos con independencia de la lengua vehículo y de intereses locales, entre otras cosas porque una obra nueva puede aparecer simultáneamente en varios idiomas; con independencia también de la verdadera fuerza de las novedades, que no necesitan tanto una capacidad subversiva como una adecuada promoción.

Novedad, generalización, hastío y olvido son más relativos bajo esas condiciones de producción y recepción: siempre hay alguien interesado en ámbitos remotos del conocimiento y la cultura, de modo que pocas cosas resultan abandonadas por todos, si bien el cauce principal para el mercado es más hegemónico que nunca y admite muy pocos escarceos por posibilidades distintas.

Eso da un enorme espacio a la re-actualización, el mercado permite más que nunca vender como novedad lo que ya estaba usado (la reinvención de mitos medievales en El código Da Vinci, por ejemplo, o de tantos guiones de películas que han servido para re-makes).

Por todas esas razones, el cambio en los códigos literarios es ahora mucho más parecido al que se observa en las lenguas naturales: más que innovaciones radicales, encontramos tendencias y mínimas desviaciones casi inconscientes que progresivamente van siendo asumidas por un conjunto normativo. Cada género literario (novela negra, fantasía, ciencia-ficción, etc.) presenta su particular norma dialectal. Esa norma es siempre implacable, pero también siempre está variando imperceptiblemente su posición a consecuencia de las incontables intervenciones de los usuarios del código.

Su estudio debería pasar entonces por los métodos estadísticos que han probado su eficacia en el estudio del cambio lingüístico. 


\section{REFERENCIAS BIBLIOGRÁFICAS}

ANÓNIMO (1993). Libro del Caballero Zifar. Cristina González (ed.). Madrid: Cátedra.

ANGELET, C. (1999). “Le topos du manuscrit trouvé: considerations historiques et typologiques”.

En Le topos du manuscrit trouvé. Hommages à Christian Angelet, Jan Herman et Fernand Hallyn (eds.), XXXI-LIV. Louvain: Peeters.

(2003). “De la préface au roman: la doctrine classique mise à l'épreuve du récit”. En Recueil de préfaces de romans du XVIIle siècle. Volume Il: 1751-1800, Christian Angelet et Jan Herman (eds.), 9-48. Saint-Étienne / Leuven: Publications de l'Université de Saint-Étienne / Presses Universitaires de Louvain.

DUCROT, O.; TODOROV, T. (1995). Diccionario enciclopédico de las ciencias del lenguaje. Buenos Aires: Siglo XXI.

EAGLETON, T. (2009). La novela inglesa. Una introducción. Madrid: Akal.

ECO, U. (1989). La estructura ausente. Barcelona: Lumen. (2000). Tratado de semiótica general. Barcelona: Lumen.

GARRIDO ARDILA, J. A. (2014). Cervantes en Inglaterra: El "Quijote" y la novela inglesa del siglo xviii. Alcalá: Universidad de Alcalá.

GUEVARA, A. (1993). Obras completas, I. Libro áureo de Marco Aurelio. Década de Césares. Emilio Blanco (ed.). Madrid: Biblioteca Castro-Turner.

GUZMÁN GUERRA, A. (2011). "Problemas teóricos de la falsificación literaria”. En Fakes and forgers of classical literature, Javier Martínez (ed.), 25-30. Madrid: Clásicas.

HERMAN, J. (1998). “Manuscrit trouvé et interdiction du roman". En Le roman des années trente: la génération de Prévost et de Marivaux, 103-106. Saint-Étienne: Université de Saint-Étienne. KANY, C. F. (1937). The beginnings of the epistolary novel in France, Italy, and Spain. Berkeley: University of California Press.

LABOV, W. (2006). Principios del cambio lingüístico. Volumen 2: Factores sociales. Madrid: Gredos. MILLET, B. (2007). “Ceci n'est pas un roman". Lévolution du statut de la fiction en Angleterre de 1652 à 1754. Leuven: Peeters.

PÉREZ, N. (1805). El Anti-quixote. Madrid: Imprenta de Justo Sánchez.

PLAZENET, L. (1999). “Origine de la fable ou alibi romanseque? Les vicisitudes du manuscrit trouvé chez les imitateurs d'Héliodore en France aux XVle et XVIle siècles". En Le topos du manuscrit trouvé. Hommages à Christian Angelet, Jan Herman et Fernand Hallyn (eds.), 4760. Louvain: Peeters.

RICO, F. (1998). "Introducción". En Lazarillo de Tormes, 11-139. Madrid, Cátedra. (2000): La novela picaresca y el punto de vista. Barcelona: Seix Barral.

RODRíGUEZ DE MONTALVO, G. (2001). Amadís de Gaula. Juan Manuel Cacho Blecua (ed.). Madrid: Cátedra.

RUTHVEN, K. K. (2001). Faking literature. Cambridge: Cambridge University Press. 
CONTRIBUCIONES INDIVIDUALES A LOS CÓDIGOS DE LA FICCIÓN MODERNA. AVATARES DEL "MANUSCRITO ENCONTRADO" A PARTIR DE LA FALSIFICACIÓN

SALES DASÍ, E. J. (2004). La aventura caballeresca. Alcalá: Centro de Estudios Cervantinos.

SAUSSURE, F. (1995 [1916]). Curso de lingüística general. Madrid: Alianza.

scudéry, M. (en línea). Artamène ou le Grand Cyrus, Institut de Littérature Française Moderne,

Claude Bourqui (dir.), Université de Neuchâtel: http://www.artamene.org/cyrus1. $x m l$ ?partie $=1 \&$ livre $=A[24 / 11 / 2015]$.

Tacca, Ó. (1973). Las voces de la novela. Madrid: Gredos.

Recibido el 13 de enero de 2016.

Aceptado el 16 de noviembre de 2016. 
